\title{
Comunicación sobre COVID-19 en Twitter: liderazgo y dialéctica Presidentes de México, España, Estados Unidos
}

\section{Communication about COVID-19 on Twitter: \\ leadership and dialectics Presidents of Mexico, Spain, United States}

Rogelio del Prado Flores ${ }^{1, \mathrm{a}}$ 0000-0002-2181-2724

Rebeca Illiana Arévalo Martínez ${ }^{1, \mathrm{~b}}$ 0000-0003-1163-6752

Genny Elizabeth Góngora Cuevas ${ }^{1, \mathrm{c}} \underline{0000-0003-3059-4818}$

${ }^{1}$ Universidad Anáhuac, México.

arogelio.delprado2@anahuac.mx

brebeca.arevalo@anahuac.mx

Recibido el: 02/07/2021

'genny.gongora@,anahuac.mx

Aprobado el: $12 / 11 / 2021$

Publicado el: 15/12/2021

\section{Resumen}

El artículo trata sobre la comunicación en redes sociales acerca de la COVID-19 y su impacto en los usuarios y tiene como objetivo analizar los mensajes de los presidentes de tres países (España, México y Estados Unidos) en Twitter a la luz de las categorías de liderazgo integrador y pragmático presentes en su contenido y relacionarlos con la dialéctica positiva o negativa que generan entre los usuarios, con el fin de identificar el impacto que tiene el discurso presidencial de la COVID-19. La metodología es mixta con análisis de contenido de los mensajes y pruebas estadísticas sobre la interacción con usuarios en los tweets emitidos por los presidentes entre el 15 de marzo y 15 de abril 2020 sobre COVID-19 y $1 \%$ de los comentarios de los usuarios. Entre los principales hallazgos del análisis de contenido se encuentra que los tres presidentes muestran un liderazgo pragmático. En el análisis de la interacción, en México se observan más favoritos, mientras que en España y Estados Unidos más retweets. Finalmente, los comentarios negativos en los tres países son relacionados con política, mientras que los positivos en México y España son sobre política, salud y economía; y en Estados Unidos sobre economía, política y salud.

Palabras clave: dialéctica; liderazgo; COVID-19; comunicación; twitter.

\begin{abstract}
The article is about communication on social media about COVID-19 and its impact on users and aims to analyze the messages on Twitter of the presidents of three countries (Spain, Mexico and the United States) with categories of integrative leadership and pragmatic leadership present in its content and relate them to the positive or negative dialectic that they generate among users, in order to identify the impact of the presidential speech of COVID-19. The methodology is cuantitative and cualitative with content analysis of the messages and statistical tests on the interaction with users in the tweets issued by the presidents between March 15 and April 15, 2020 about COVID-19 and 1\% of user comments. Among the main findings of the content analysis is that the three presidents show pragmatic leadership. In the analysis of the interaction, in Mexico there are more favorites, while in Spain and the United States more retweets. Finally, the negative comments in the three countries are related to politics, while the positive ones in Mexico and Spain are about politics, health and the economy; and in the United States on economics, politics and health.
\end{abstract}

Keywords: dialectic; leadership; COVID-19; communication; twitter. 


\section{Introducción}

En diciembre de 2019 la República Popular de China alertó a la Organización Mundial de la Salud (OMS) sobre casos de una neumonía inusual (Infobae, 2020), iniciando así la pandemia más fuerte que ha padecido el mundo contemporáneo: SARS COV-2 (COVID-19) y en marzo 2020 la OMS se mostró preocupada por los altos niveles de contagios y su gravedad, así como por los altos niveles de inacción (Al Jazeera, 2020b). Esto debido a que, en casos de campañas de salud pública, el rol del gobierno es "planificar y aplicar de manera inmediata estrategias de comunicación" (Castillo-Esparcia et al., 2020, p. 1). En este caso se utilizaron las redes sociodigitales para transmitir noticias, aunque éstas pusieron en riesgo la salud de las personas por ser "poco objetivas o falsas" (Aleixandre-Benavent, et al., 2020, p. 1), publicar información no verificada o errónea sobre la COVID-19 (Kouzy et al., 2020), convirtiéndose en contenido, mentiras, muy peligroso que afectaba la salud y agravaba el contagio hasta la muerte (Pérez-Dasilva et al., 2020).

Los presidentes al inicio negaron los riesgos de la pandemia. En Estados Unidos el presidente comparaba el virus con la gripe y aceptó públicamente que lo minimizaba para no crear pánico (Navarro 2020). En España se utilizó un mensaje de calma para sobreproteger a la población, aunque esto después chocó con la realidad (Costa-Sánchez y López-García, 2020). En México el presidente decía que no pasaba nada y seguía abrazando a seguidores en actos públicos a pesar de reconocer la existencia del virus (Robinson, 2020). Para el 13 de marzo de 2020 Estados Unidos declaró emergencia nacional (A1 Jazeera, 2020a), el 30 de marzo España era el tercer país con mayor número de muertes (Gómez, 2020) aunque lo minimizaba publicando que dos casos sospechosos provenientes de China daban negativo (Linde, 2020), y hacia fines de marzo México iniciaba el aislamiento para evitar el incremento de contagios graves (Samerón, 2020), los cuales llegaron a 1 millón 175 mil 850 en diciembre 2020 (Mancilla, 2020).

Derivado de lo anterior esta investigación analiza el impacto de la comunicación en Twitter de los presidentes de México, España y Estados Unidos sobre la COVID-19 a partir de una metodología mixta que conjunta liderazgo, interacción y dialéctica. Se contribuye al conocimiento con un análisis de contenido de los tweets de los presidentes a la luz del liderazgo en comunicación y de los comentarios de usuarios respecto a la dialéctica positiva o negativa que se genera; así como a través de la cuantificación de la interacción. Es relevante el papel del liderazgo en comunicación de los presidentes con la interacción diferenciada que producen entre sus seguidores, así como la dialéctica positiva o negativa hacia otros temas, no sólo la salud, sino la economía y la política, por medio de la cual muestran su afinidad o rechazo a la figura presidencial.

El análisis de la comunicación gubernamental es indispensable para prevenir la transmisión de enfermedades altamente contagiosas como la COVID-19 (Anderson et al., 2020), informar sobre síntomas y su seguimiento (Heyman y Shindo, 2020), combatir la proliferación de rumores (Fernández, 2020) y detener contagios (Green et al., 2020). En las crisis sanitarias globales se necesitan líderes resilientes que apliquen soluciones con visión del presente y futuro (Meza, 2020) con comunicación por diversos medios (Arista, 2020) y alcances (Ginel, 2020), manteniendo escucha y atención a la oposición racional de argumentos para superar el conflicto en aras de una síntesis progresiva que beneficie la cultura de una población (Hegel, 1994). Una dialéctica negativa de descoordinación en la información provoca "personas menos capaces de hacer las atribuciones correctas de la información gubernamental es lo más crítico de la respuesta a la crisis." (Moreno et al., 2020, p. 11). La aplicación de la dialéctica a la responsabilidad de los diferentes actores llevaría a un consumo crítico de noticias (Segado et al., 2020).

Por otra parte, el análisis de la comunicación de los presidentes sobre la COVID-19 parte de las seis capacidades individuales de excelencia de liderazgo en comunicación (Meng y Berger, 2013) las cuales definen la toma de decisiones del líder para lograr resultados a través de un capital determinado. Hay dos tipos de líderes: 1) pragmático que prioriza atención de crisis y transparencia, se orienta a la formación de capital económico por medio de conocimiento, ética, decisión y comunicación bidireccional; 2) integrador que prioriza la atención al talento y globalización para formar capital simbólico utilizando la vinculación con otros, la visión y soporte (Arévalo, 2019). 
Finalmente, las redes sociodigitales funcionan bajo la lógica del mercantilismo, individualismo y con estructuras de dominación, bajo la promesa paradójica de un nuevo nivel de integración y colaboración (Fuchs, 2016); "por medio de la libertad individual se realiza la libertad del capital" (Han, 2014a). En particular, Twitter presenta una agenda sensible a la participación ciudadana generando una mayor permanencia si coinciden con los trending topics (Pérez-Díaz, 2020). Esta red sociodigital busca generar un tipo de tolerancia entendida como libertad de oposición racional (Marcuse, 1969), enarbolando una forma de comunicación libre cuando en realidad se ejerce censura, un poder de exclusión incluso sin respeto a los derechos humanos (Artículo 19, 2020). En las redes sociales digitales se crea la ilusión de un pensamiento dialéctico entre el individuo y la sociedad de internautas, lo cual puede ser una ficción dado que el pensamiento dialéctico es por esencia bidimensional (Marcuse, 1964). La dialéctica permite la comprensión y el entendimiento mutuo a través de conceptos que "trascienden lo dado de la realidad social en la dirección de otra estructura histórica que está presente como una tendencia en la realidad dada" (Marcuse, 1968, p. 86).

El objetivo de esta investigación fue analizar la dialéctica positiva o negativa que generan los mensajes en Twitter sobre la COVID-19 de los presidentes de España, México y Estados Unidos con los usuarios, utilizando las categorías de liderazgo en comunicación.

\section{Metodología}

Se analizaron los tweets emitidos por los presidentes referentes a la COVID-19 entre el 15 de marzo y el 15 de abril de 2020 tomando una muestra por conveniencia no probabilística y no aleatoria para lo cual se tomaron el $100 \%$ de los tweets de los presidentes cuya temática estuviera relacionada con la COVID-19 (213 tweets analizados en ese período) y con base en eso se analizó una muestra de los comentarios con un nivel de confianza del 95. Se analizaron 4,345 comentarios, lo que constituye una muestra representativa suficiente para el total de comentarios recibidos en ese período que fue de 3'446,622. Para la recolección de los datos se hizo una revisión directa en la página de Twitter. Los datos de interacción fueron analizados con el programa SPSS versión 26, para lo cual se categorizaron de acuerdo al país del presidente.
El análisis de contenido de los tweets de los presidentes se hizo con base en las categorías de liderazgo pragmático (Crisis, Transparencia, Conocimiento, Ética, Decisión y Bidireccional) y liderazgo integrador (Talento, Globalización, Vinculación, Visión y Soporte). La interacción se analizó cuantificando retweets y favoritos. Los comentarios fueron clasificados en dialéctica positiva o negativa, considerando el tema al que hacían referencia (salud, economía, familia, política y ética ciudadana). En cuanto a los usuarios se analizó su número de seguidores para relacionarlo con los comentarios emitidos. Así se plantearon las siguientes hipótesis de investigación: El país del presidente es independiente de la interacción que tienen sus mensajes; los retweets que tienen sus mensajes así como los comentarios positivos $\mathrm{y}$ negativos en sus diferentes categorías son independientes del país; y la moda en la escala de valores de los seguidores con comentarios a los tweets de los presidentes es la misma en los tres países.

En el caso del análisis cualitativo se buscó identificar la frecuencia de palabras en los tweets de cada presidente, así como la relación entre el tweet del presidente y la cantidad de comentarios recibidos. Finalmente, se logró tener una visión de la dialéctica positiva o negativa generada entre los usuarios a partir del tweet de cada presidente.

La metodología mixta que considera el análisis cuantitativo y cualitativo permite no sólo saber cuántos tweets tuvieron comentarios positivos o negativos, dialéctica, o bien conocer la interacción si se marcaron como favoritos o su independencia o correlación con el país del presidente, sino que también permite analizar los sentimientos de las personas, sus preocupaciones principales y el discurso del odio a través del análisis del contenido y el conteo de palabras que aparecen con mayor frecuencia. La metodología mixta permite tener un panorama más amplio de la situación en el momento de la investigación en estos tres países en torno a la COVID-19 y su impacto en los usuarios.

Para analizar el liderazgo en comunicación de cada presidente se tomaron en consideración los tweets, en la temática de su contenido, el tono del mensaje y el fondo del mismo clasificándolos en conocimiento, decisión, ética, soporte, visión, vinculación, bidireccional, crisis, transparencia, talento y globalización. Se usó la frecuencia 
observada en cada una de estas clasificaciones para presentarlas en una gráfica.

Las definiciones operacionales fueron las siguientes: 1) dialéctica entendida como los comentarios que abonan al diálogo o que son destructivos; 2) Dialéctica positiva como existencia de mensajes positivos en temas de salud, economía, familia, política o ética ciudadana; 3) Dialéctica Negativa como existencia de mensajes negativos que no abonan al diálogo en temas de salud, economía, familia, política o ética ciudadana; 4) Liderazgo Pragmático teniendo como prioridades: Crisis, Transparencia, Conocimiento, Ética, Decisión y Bidireccional; 5) Liderazgo integrador estando preparado para afrontar con eficacia las crisis, demostrar transparencia al lidiar con la creciente demanda de rendición de cuentas así como una ética medida como una fuerte orientación al deber ser y a los valores que guíen las acciones, así como participar en toma de decisiones estratégicas, una comunicación bidireccional y poder compartido.

En cuanto a la escala de odio, los comentarios se clasificaron de acuerdo al análisis de su contenido: 1) bromas hirientes sobre equivocaciones en lenguaje; 2) bromas hirientes sobre sexo, edad, condición social, raza; 3) chantajear; 4) celar; 5) descalificar; 6) ridiculizar; 7) humillar; 8) intimidar por cualquier razón; 9) controlar o prohibir acciones; 10) amenazas para destruir artículos personales; 11) amenazas de manosear; 12) amenazas de pellizcar, arañar; 13) amenazas de cachetear; 14) amenazas de golpear; 15) amenazar con secuestro; 16) amenazas de Violar / abuso sexual; 17) amenaza de mutilar; 18) amenazas de muerte a familiares; 19) amenazar de muerte; 20) amenazar de muerte con imágenes de armas.

\section{Resultados}

\section{Resultados cuantitativos}

En el caso de la hipótesis sobre si el país del presidente es independiente de la interacción de los seguidores, se encontró que sí tiene dependencia con el país de que se trate, es decir que un tweet del presidente de Estados Unidos en cuanto al número de interacciones (favoritos o retweets) no es igual al de México o España. Este cálculo se obtuvo utilizando la prueba de chi-cuadrado donde el estadístico de prueba es .000 siendo menor al nivel de significancia fijado en $.05(\mathrm{p}<.05)$ para tener una confianza de .95 o $95 \%$. Al analizar los datos de manera relativa, observamos en Estados Unidos y España que las reacciones mayores de los usuarios se dan en retweets, seguidas de favoritos; mientras que en México la interacción es en forma de favoritos en $66.1 \%$.

Con respecto a la hipótesis referente a si el país del presidente es independiente de los retweets que tienen sus mensajes se procedió a hacer un análisis de regresión lineal para determinar la correlación entre ambas variables por lo que observa el liderazgo del presidente medido en el número de tweets por cada comentario positivo o negativo. Es decir, la dialéctica positiva o negativa a partir del mensaje del presidente, por cada tweet del presidente la interacción es de 3,877 comentarios de sus seguidores, y esto se puede explicar en un $76 \%$ por el país del presidente ya que el coeficiente de correlación de Pearson es de .760 y el coeficiente $\beta$ es 3.877 (Tabla 1 y Tabla 2).

Tabla 1. Resumen del modelo de regresión para comentarios de seguidores a los tweets de los presidentes.

\begin{tabular}{llllll}
\hline Modelo & $\mathbf{R}$ & $\begin{array}{l}\text { R } \\
\text { cuadrado }\end{array}$ & $\begin{array}{l}\text { R cuadrado } \\
\text { ajustado }\end{array}$ & $\begin{array}{l}\text { Error estándar } \\
\text { de la estimación }\end{array}$ & $\begin{array}{l}\text { Durbin- } \\
\text { Watson }\end{array}$ \\
\hline 1 & $.760 \mathrm{a}$ & .577 & .575 & 68850.821 & 1.581 \\
\hline
\end{tabular}

Tabla 2. Modelo de regresión lineal para retweets y comentarios de los presidentes.

\begin{tabular}{|c|c|c|c|c|c|c|}
\hline \multirow{2}{*}{\multicolumn{2}{|c|}{ Modelo }} & \multicolumn{2}{|c|}{$\begin{array}{l}\text { Coeficientes no } \\
\text { estandarizados }\end{array}$} & \multirow{2}{*}{$\begin{array}{l}\text { Coeficientes } \\
\text { estandarizados } \\
\text { Beta } \\
\end{array}$} & \multirow[t]{2}{*}{$\mathbf{T}$} & \multirow[t]{2}{*}{ Sig. } \\
\hline & & B & Desv. Error & & & \\
\hline \multirow[t]{2}{*}{1} & (Constante) & 41831.153 & 6817.576 & & 6.136 & .000 \\
\hline & $\begin{array}{l}\text { Número de } \\
\text { comentarios }\end{array}$ & 3.877 & .245 & .760 & 15.806 & .000 \\
\hline
\end{tabular}


Se realizó la prueba chi cuadrada para comprobar la hipótesis que plantea una independencia entre el número de comentarios positivos en sus diferentes categorías y el país. Se obtuvo en la prueba una p-value .000 que es menor a .05 , por lo que se rechaza la hipótesis de independencia. Los comentarios positivos en todos los casos incluyen palabras que validan las decisiones, afirmaciones, acciones o propuestas del presidente. Es decir, se puede afirmar que sí existe una dependencia entre el país y el número de comentarios positivos que apoyan al presidente en lo que está anunciando en su tweet, siendo diversos en cuanto al contenido de acuerdo con la temática que se está abordando. Analizando la dialéctica positiva, en el caso de México y España se presentó principalmente en el tema de política, seguido de salud y economía; mientras que en Estados Unidos fue en el tema de economía, seguido de política y salud. Destaca que en el caso de México no hay ningún comentario relacionado con la familia, mientras que en Estados Unidos y España existen porcentajes similares de comentarios en esa categoría (Tabla 3 ).

Tabla 3. Comentarios Positivos.

\begin{tabular}{llcccccc}
\hline & Salud & Economía & Familia & Política & Ética ciudadana & Total \\
\hline \multirow{2}{*}{ México } & \% dentro de País & $14.9 \%$ & $11.9 \%$ & $0.0 \%$ & $70.8 \%$ & $2.4 \%$ & $100.0 \%$ \\
\cline { 2 - 8 } & $\%$ del total & $1.4 \%$ & $1.1 \%$ & $0.0 \%$ & $6.7 \%$ & $0.2 \%$ & $9.5 \%$ \\
\hline \multirow{2}{*}{ EU } & $\%$ dentro de País & $22.6 \%$ & $39.2 \%$ & $1.5 \%$ & $29.7 \%$ & $7.1 \%$ & $100.0 \%$ \\
\cline { 2 - 8 } & $\%$ del total & $19.6 \%$ & $34.0 \%$ & $1.3 \%$ & $25.8 \%$ & $6.2 \%$ & $86.9 \%$ \\
\hline \multirow{2}{*}{ España } & $\%$ dentro de País & $25.4 \%$ & $1.6 \%$ & $0.0 \%$ & $63.5 \%$ & $9.5 \%$ & $100.0 \%$ \\
\cline { 2 - 8 } & $\%$ del total & $0.9 \%$ & $0.1 \%$ & $0.0 \%$ & $2.3 \%$ & $0.3 \%$ & $3.6 \%$ \\
\hline \multirow{2}{*}{ Total } & $\%$ dentro de País & $21.9 \%$ & $35.2 \%$ & $1.3 \%$ & $34.8 \%$ & $6.7 \%$ & $100.0 \%$ \\
\hline
\end{tabular}

Se analizaron los comentarios que expresaban en su contenido una oposición o crítica a lo que el presidente mencionaba en su tweet con la intención de saber si el número de éstos en sus diferentes categorías era independiente del país (Tabla 4). Ser realizó la prueba chi cuadrada para comprobar esta hipótesis obteniendo una p-value .000 que es menor a .05 , por lo que se rechaza la hipótesis de independencia entre país y categoría de comentario negativo. Los comentarios negativos en todos los casos hacen referencia a descalificaciones a las decisiones, acciones o propuestas del presidente y se evalúan en la escala de odio y valores ya mencionadas en la metodología.

Tabla 4. Los tres países con sus comentarios negativos en las cinco categorías de análisis.

\begin{tabular}{llcccccc}
\hline & & \multicolumn{5}{c}{ Comentarios Negativos } & \multirow{2}{*}{ Total } \\
\cline { 2 - 8 } & & Salud & Economía & Familia & Política & Ética Ciudadana & \\
\hline \multirow{2}{*}{ México } & $\%$ dentro de País & $26.9 \%$ & $16.4 \%$ & $0.0 \%$ & $55.4 \%$ & $1.2 \%$ & $100.0 \%$ \\
\cline { 2 - 8 } & $\%$ del total & $3.2 \%$ & $2.0 \%$ & $0.0 \%$ & $6.7 \%$ & $0.1 \%$ & $12.1 \%$ \\
\hline \multirow{2}{*}{ EU } & $\%$ dentro de País & $19.6 \%$ & $36.4 \%$ & $0.2 \%$ & $40.1 \%$ & $3.7 \%$ & $100.0 \%$ \\
\cline { 2 - 7 } & $\%$ del total & $14.0 \%$ & $26.1 \%$ & $0.1 \%$ & $28.7 \%$ & $2.6 \%$ & $71.6 \%$ \\
\hline \multirow{2}{*}{ España } & $\%$ dentro de País & $8.9 \%$ & $13.7 \%$ & $0.7 \%$ & $75.6 \%$ & $1.1 \%$ & $100.0 \%$ \\
\cline { 2 - 7 } & $\%$ del total & $1.5 \%$ & $2.2 \%$ & $0.1 \%$ & $12.4 \%$ & $0.2 \%$ & $16.4 \%$ \\
\hline \multirow{2}{*}{ Total } & $\%$ dentro de País & $18.7 \%$ & $30.3 \%$ & $0.3 \%$ & $47.8 \%$ & $3.0 \%$ & $100.0 \%$ \\
\hline
\end{tabular}

Fuente: Elaboración propia.

Se observó una dialéctica negativa coincidente en los tres países en cuanto a la categoría de política. En España y Estados Unidos se colocó en segundo lugar economía seguido de salud, mientras que en México en segundo lugar salud y en tercer lugar economía. Para comprender mejor la dialéctica positiva o negativa de los comentarios a los tweets de los presidentes, se extrajeron del perfil de usuarios únicamente aquéllos que tenían más de 10,000 seguidores (perfil más alto de usuario, denominados influencers) y se analizó de forma descriptiva su actividad comentando los tweets de los presidentes (Tabla 5). 
Tabla 5. Análisis de dialéctica positiva o negativa vs. número de usuarios con más de 10,000 seguidores.

\begin{tabular}{llllll}
\hline País & $\begin{array}{l}\text { Número de } \\
\text { usuarios }\end{array}$ & \multicolumn{2}{c}{ Dialéctica positiva } & \multicolumn{2}{c}{ Dialéctica negativa } \\
\cline { 3 - 6 } & $\begin{array}{l}\text { Usuarios que } \\
\text { comentaron }\end{array}$ & $\begin{array}{l}\text { Moda en la escala } \\
\text { de valor } \\
\text { ciudadano }\end{array}$ & $\begin{array}{l}\text { Usuarios que } \\
\text { comentaron }\end{array}$ & $\begin{array}{l}\text { Moda en la } \\
\text { escala de odio }\end{array}$ \\
\hline España & 20 & 5 & 5 & 15 & $\begin{array}{l}1 \\
\text { interés público }\end{array}$ \\
\hline $\begin{array}{llll}\text { Estados } \\
\text { Unidos }\end{array}$ & 79 & 77 & 9 solidaridad & 2 & 6 \\
& & & & $\begin{array}{l}\text { entorno } \\
\text { cultural y } \\
\text { ecológico }\end{array}$ \\
\hline México & 28 & 27 & 8 & 1 & 1 \\
& & & & & interés público \\
\hline
\end{tabular}

Como se puede observar, en el caso de Estados Unidos se encontraron un total de 79 usuarios con el perfil de más de 10,000 seguidores, en España 20 y en México 28. Ejemplificando con el caso de Estados Unidos, lo que se puede ver en el Cuadro 6, particularmente en dialéctica positiva se encontraron 77 usuarios, de los cuales 35 tuvieron una moda en la escala de valor ciudadano de 9 que es el puntaje más alto y significa solidaridad; mientras que en dialéctica negativa fueron 2 usuarios con una moda en la escala del valor ciudadano de entorno cultural y ecológico. Asimismo se observa que la moda de la escala de odio de los usuarios con comentarios negativos no es la misma en los tres países, aunque hay una coincidencia en el caso de España y México en la moda de la dialéctica negativa en interés público. $\mathrm{Al}$ analizar la estadística descriptiva se observa que la moda en la escala de valores de los seguidores con comentarios a los tweets de los presidentes no es la misma en los tres países.

\section{Resultados cualitativos}

Por otra parte, se realizó un análisis de contenido de todos los tweets de los presidentes y se elaboró una nube de texto en la que se muestran aquellas palabras con mayor frecuencia en cada país. En México, las palabras que utilizó el presidente con mayor frecuencia fueron: médicos, COVID-19, coronavirus, cuidando, equipo, salud, hospitales. Su lenguaje refleja su estilo de liderazgo pragmático al utilizar las categorías de este tipo, como son: conocimiento al referirse a los médicos, decisión sobre la no saturación de hospitales, la adquisición de equipo médico e insumos, así como la búsqueda de reflejar su ética y el sentido bidireccional al mencionar continuamente la palabra cuidando que es un verbo incluyente que implica la participación de todos. La continua referencia a COVID-19, médicos, coronavirus, hospitales y salud es reflejo de su conocimiento y decisión para atender la crisis de salud (Gráfica 1).

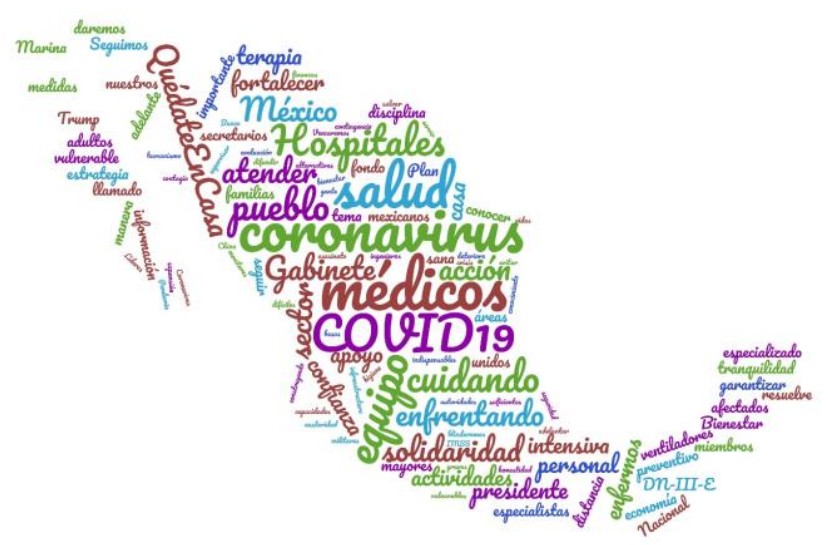

Gráfica 1. Tweets del presidente de México.

El presidente de Estados Unidos usó con mayor frecuencia la palabra Will cuya connotación es realizar, lograr. Es decir, aquello que da por sentado y en la mayor parte de sus mensajes significó que el virus se combatirá con éxito, mostrando un liderazgo pragmático, es decir priorizando la atención de crisis, transparencia, conocimiento, decisiones y comunicación bidireccional. Aparece la palabra New York porque fue el centro de la pandemia, y en el periodo analizado, la mayoría de los recursos se canalizaban a ese Estado. Destaca la palabra Cuomo, nombre del alcalde de la ciudad con un rol importante para combatir la pandemia. También destacan palabras sobre la construcción de hospitales y empresas que apoyaron en la producción de ventiladores. En cuanto a la palabra States, los estados que conforman la Unión Americana pedían apoyo al gobierno federal. El discurso se centra en la grandeza del pueblo americano, las acciones del presidente, China, 
virus, enemigo e invisible que se relacionan con el coronavirus (Gráfica 2).

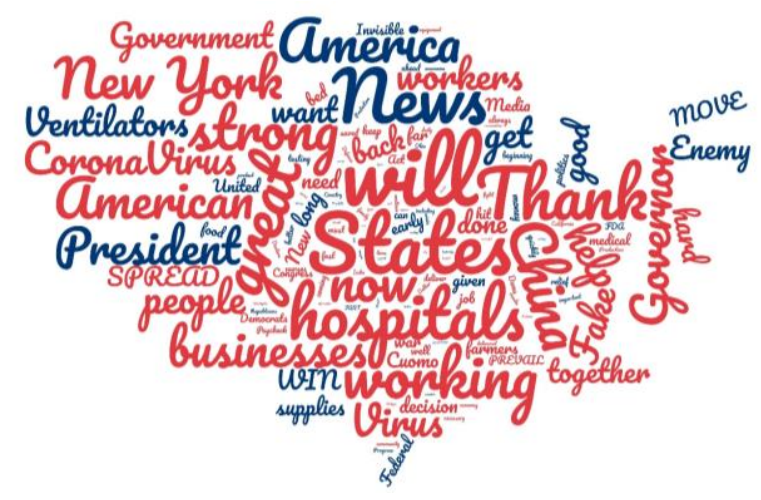

Gráfica 2. Tweets del presidente de Estados Unidos.

En cuanto al Presidente de España, se observa COVID-19, sociedad, España, un llamado a la unidad, la lucha, la solidaridad, y remarcar los momentos difíciles que vivía España ante la pandemia. El contenido de sus mensajes es congruente con su liderazgo predominante que es pragmático, utiliza categorías de crisis y la necesidad de unirse para superarla; conocimiento que tienen para salir adelante al mencionar cuidado, protección responsabilidad; y decisión que los va a llevar a enfrentar por medio de la sociedad, la unidad y la solidaridad. Las palabras de mayor frecuencia son reflejo de su invitación a unirse ante el coronavirus, mostrar que tiene dominio de la situación y que puede manejar la crisis si cuenta con la unidad y solidaridad de todos (Gráfica 3).

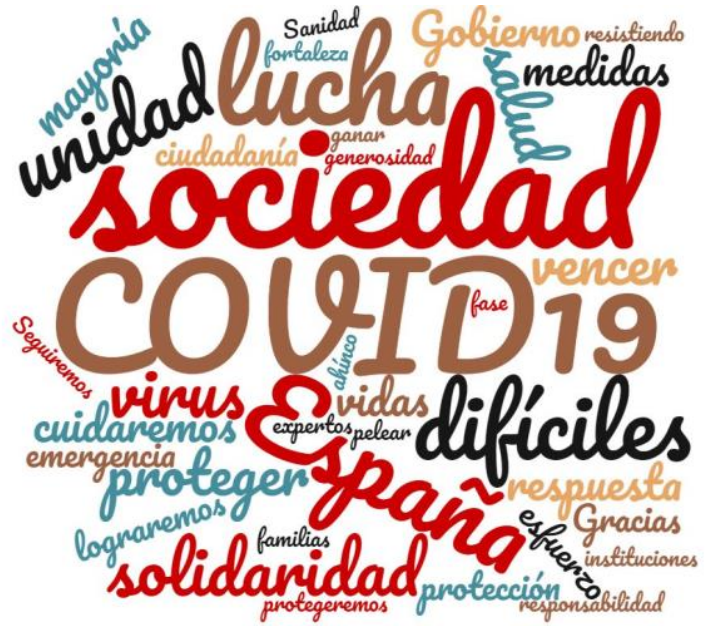

Gráfica 3. Tweets del presidente de España.
En el análisis de las dimensiones del liderazgo de cada presidente se observa que el Presidente de Estados Unidos en la escala de ética tiene una calificación de cero, mientras que su mayor dimensión de liderazgo es decisión, seguida de crisis. En cuanto al presidente de México y España las calificaciones en sus dimensiones de liderazgo son muy similares, destacando en primer lugar las dimensiones de conocimiento, decisión $\mathrm{y}$ vinculación, $\mathrm{y}$ en último lugar las de crisis $\mathrm{y}$ globalización (Gráfica 4).

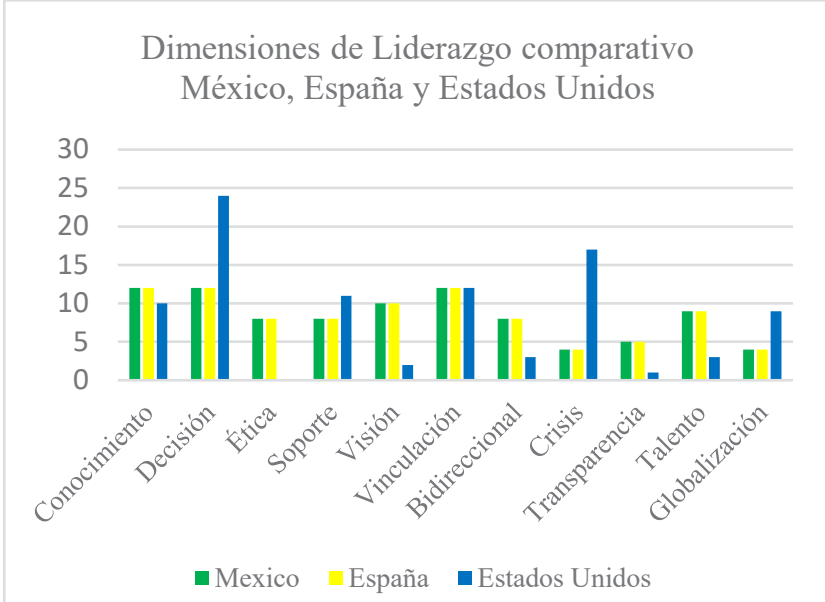

Gráfica 4. Dimensiones de Liderazgo de los Presidentes de México, España y Estados Unidos.

Reuniendo las dimensiones que implica cada tipo de liderazgo, pragmático o integrador, se puede observar que los tres presidentes están inclinados al liderazgo pragmático, aunque con distinto nivel en sus dimensiones como puede observarse en la Gráfica 5. En el caso del presidente de Estados Unidos, su liderazgo pragmático es mucho más definido por encima del integrador, mientras que en los presidentes de España y México está más equilibrado. Si se analiza el liderazgo pragmático del presidente de Estados Unidos tiene un mayor contenido de decisión, crisis y conocimiento; siendo sus dimensiones más grandes de liderazgo integrador la visión y el soporte. En cuanto al presidente de México y España coinciden en cuanto a que su liderazgo pragmático tiene un mayor contenido de conocimiento y decisión; siendo sus dimensiones más grandes de liderazgo integrador la vinculación y la visión. 


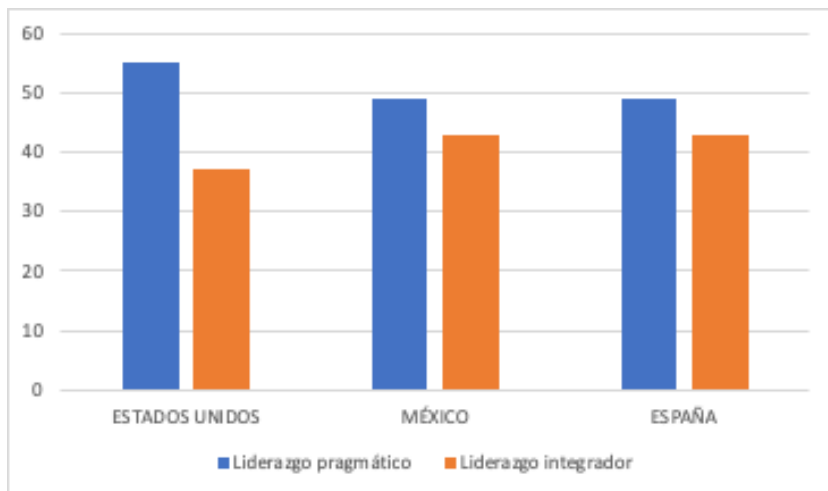

Gráfica 5. Comparativo de estilos de Liderazgo de los Presidentes de México, España y Estados Unidos reflejado en sus tweets.

Por otra parte, la dialéctica de los seguidores del presidente día a día como respuesta a los tweets del presidente se puede analizar en la Gráfica 6. Como se puede observar existe un alto número de comentarios en el tweet del presidente de Estados Unidos el día 5 de abril con más de 50,000 comentarios, mientras que los tweets de mayor número de comentarios en España y México tan solo superaron los 10,000 comentarios el día 3 de abril y 29 de marzo, respectivamente (Gráfica 6). Tweets con mayores comentarios: 1) España, 3 abril: "Gracias de corazón. Vuestra solidaridad con España nos anima en la lucha contra la pandemia del \#COVID19. Son tiempos difíciles, pero desde la generosidad y la disciplina"; 2) México, 29 marzo: "Todos a casa siempre y cuando no se tengan actividades fundamentales para el bienestar y la seguridad del pueblo. Sigamos cuidando a los adultos mayores y a los enfermos. \#QuédateEnCasa"; 3) Estados Unidos, 5 abril: "We are learning much about the Invisible Enemy. It is tough and smart, but we are tougher and smarter!".

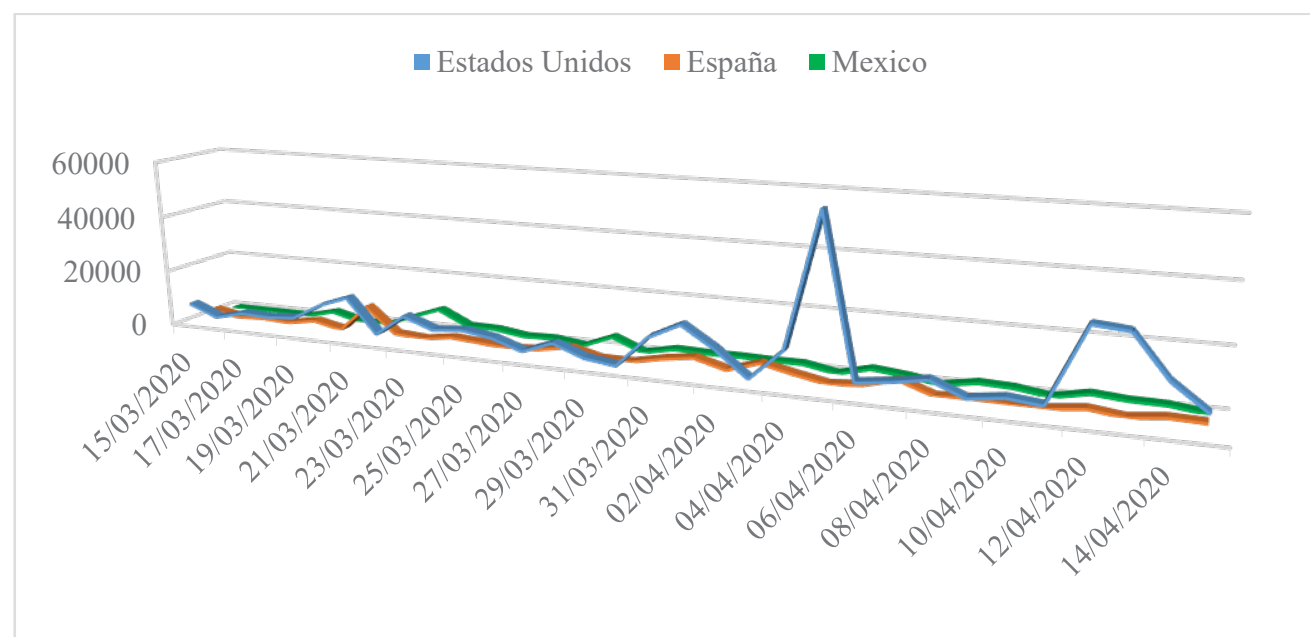

Gráfica 6. Seguimiento del número de comentarios por país y fecha.

\section{Discusión}

Como se observó en los resultados existe una relación estadísticamente importante o significativa entre la figura del presidente, su liderazgo en comunicación percibido y el contenido de su mensaje y la reacción de la dialéctica de sus seguidores en Twitter. Es decir, existe relación entre el número de retweets y los comentarios hechos por el presidente de cada país con lo que comprueba el impacto del emisor en la dialéctica. La sola conversación en Twitter no es universalmente similar, pues los usuarios de Twitter reaccionan de forma negativa al comentario del presidente a partir de lo que consideran falso. De acuerdo a lo anterior, se puede decir que en esta investigación se observó una dialéctica entre el sujeto y el objeto, dado que los mensajes de los presidentes en redes sociales reflejan la estructura social, condicionando las prácticas y viceversa; lo cual se relaciona con el tipo de liderazgo que tienen (Arévalo, 2019).

Es importante señalar que no se produce un diálogo sino que los usuarios simplemente retoman la información y van construyendo significados que recrean las estructuras ya existentes (CastilloEsparcia et al., 2020), lo cual es proclive a desencadenar una dialéctica negativa que dispersa el núcleo de la conversación; difícil de encausar las bifurcaciones de la comunicación en Twitter en una sola corriente de argumentos que consolide una estrategia de comunicación necesaria en tiempos de crisis sanitaria. Como se mencionó, la infodemia también es una situación que pone en riesgo la salud de la población (OMS, 2020; Castillo-Esparcia et al., 2020). 
Sobre la diferencia en el tipo de reacciones que generan los tweets de los presidentes, es relevante señalar que, en el caso de México, el hecho de que se tenga un mayor número de favoritos en comparación con Estados Unidos y España que tienen un mayor número de retweets, pone de manifiesto que la dialéctica en el caso de México es básicamente sujeto-objeto-sujeto con apuntalar las condiciones existentes (Navarro, 2020). Por su parte en Estados Unidos y España se privilegia la dialéctica del sujeto con la sociedad, buscando la autorrepresentación al ser emisores de información y la dialéctica del cambio al buscar el bien común (Anderson et al., 2020). En el caso de Estados Unidos, la dialéctica es positiva para el grupo de seguidores del presidente, mientras es negativa para la oposición. Este mismo juicio puede aplicarse para España y México, donde igualmente la opinión sobre la gestión de los presidentes depende de la ideología o de la posición política a la que se pertenezca.

Ahora bien, dado que la reacción en Twitter tiene una dependencia con el país de donde procede el comentario, no es posible comparar de manera directa la frecuencia de reacciones de cada tweet, no obstante, la consideración de que para los usuarios que comentan al presidente de Estados Unidos es más importante retweetear que cualquier otra reacción habla de su tendencia a la transmisión de información, mientras que en España y México pareciera que es más importante simplemente señalar como favorito el mensaje de su presidente, no conversar. Así, la dialéctica positiva y negativa está relacionada con el presidente y es reflejo de la afinidad del usuario hacia él y no sobre los mensajes en sí mismos. Es decir, el número de comentarios de seguidores está relacionado con el número de tweets que el presidente emite independientemente de que su comentario pueda ser positivo o negativo, simplemente expanden la misma información presidencial dado que los comentarios positivos o negativos ya están predispuestos, no cambian de acuerdo al tema en sí mismo sino a la afinidad con la figura presidencial.

Finalmente, sobre los tweets que recibieron el mayor número de comentarios, como se pudo observar en la Gráfica 6, el mensaje del presidente de España alienta a la unión, solicita el apoyo de los usuarios de Twitter para luchar contra la pandemia (Heyman \& Shindo, 2020); el presidente de México está orientado directamente a la acción requerida para detener los contagios; mientras que el de Estados Unidos se enfoca en motivar diciendo que son más inteligentes que el virus (Hegel, 1994; Segado et al., 2020). En este sentido, el mayor número de comentarios en el caso de España y México se dio cuando el tweet del presidente estuvo centrado en la unidad y el cuidado de la salud de manera colectiva, mientras que en el caso de Estados Unidos se dio cuando el presidente hizo un tweet muy lleno de orgullo por ser los mejores, apelando a su inteligencia como sociedad y su poder frente a la pandemia.

\section{Conclusiones}

La investigación y análisis sobre los efectos de la comunicación en Twitter en México, España y Estados Unidos permite analizar el tipo de liderazgo en comunicación de los presidentes en situación de crisis sanitaria por la enfermedad de la COVID-19. Las principales diferencias se notan al comparar Estados Unidos contra México y España; es decir, no existen grandes diferencias en cuanto a opiniones entre México y España. Aún cuando una clasificación extensa de los usuarios demuestra que las características de éstos no influyen en la variable liderazgo. Asimismo, tampoco se demuestra una relación entre el liderazgo y la inclinación a poner comentarios positivos $o$ negativos en alguna categoría, lo que comprueba que la conversación no se construye a partir del tipo de usuario sino en relación al tweet original del Presidente, permaneciendo la tendencia en lo positivo o negativo.

La dialéctica que se generó en Twitter en el periodo analizado en los tres países está determinada por el arraigo partidista de los usuarios, el contexto ideológico del país, el pluralismo de visiones muchas de ellas contrapuestas, el individualismo y las estructuras del estado encargadas de atender la crisis sanitaria. La conversación en Twitter refleja hasta cierto punto las opiniones confrontadas de la realidad social, y la combinación de elementos y posturas diferentes dentro de una temática. Las mayores reacciones de los usuarios a un comentario del presidente de Estados Unidos son cuando se trasmite la idea de ganar un combate al enemigo, en este caso un virus. El mensaje del presidente de España que genera mayores reacciones mezcla emociones de agradecimiento, de reconocimiento a la solidaridad, con una palabra bélica. De igual forma la comunicación del presidente de México 
relaciona temas diversos como la preocupación por la economía del país con estrategias de confinamiento para detener la cadena de contagios.

Habría que comparar las acciones reales de los ciudadanos con sus reacciones en Twitter para tener matices de la realidad social de cada país. De la misma forma, es pertinente una evaluación objetiva de las acciones emprendidas por cada presidente para conocer si las reacciones en Twitter están acordes con la realidad. El liderazgo percibido es una cuestión manejada por los especialistas que componen los departamentos de comunicación de los gobiernos, mientras que la dialéctica es una cuestión que se necesita fomentar entre la población para crear una cultura basada en el diálogo abierto y plural.

\section{Referencias}

Aleixandre-Benavent, R., Castelló-Cogollos, L. y Valderrama-Zurlán, J.C. (2020). Información y comunicación durante los primeros meses de Covid-19. Infodemia, desinformación y papel de los profesionales de la información. Profesional de la Información, 29(4), e290408. 10.3145/epi.2020.jul.08

Al Jazeera (2020a). Coronavirus pandemic: All the latest updates. 13 de marzo de 2020. https://www.aljazeera.com/news/2020/3/13/ coronavirus-pandemic-all-the-latest-updates

Al Jazeera (2020b). Pandemic: WHO declares coronavirus a major global threat. 11 de marzo de 2020. https://www.aljazeera.com/ news/2020/3/11/pandemic-who-declarescoronavirus-a-major-global-threat

Anderson, R., Heesterbeek, H., Klinkenberg, D. y Hollingsworth, T.D. (2020). How will country-based mitigation measures influence the course of the COVID-19 epidemic?". The Lancet, 395(10228), 931-934. 10.1016/ $\underline{\mathrm{S} 0140-6736(20) 30567-5}$

Arévalo, R.I. (2019). Comunicación integral para las organizaciones: liderazgo y creación de valor. Salamanca: Comunicación social ediciones y publicaciones

Arista, L. (2020). Gobierno prevé fortalecer medidas contra COVID-19 en zonas con más contagios. Expansión política. https://politica. expansion.mx/mexico/2020/04/16/gobiernopreve-fortalecer-medidas-contra-covid-19en-zonas-con-mas-contagios

Artículo 19 (2020). Mentiras virales: La desinformación y el coronavirus. https:// articulo19.org/wp-content/uploads/2020/03/ A19 COVID19 2020-V2.pdf

Castillo-Esparcia, A., Fernández-Souto, A. y Puentes-Rivera, I. (2020). Comunicación política y Covid-19. Estrategias del Gobierno de España. Profesional de la información, 29(4), e290419. 10.3145/epi.2020.jul.19

Costa-Sánchez, C. y López-García, X. (2020). Comunicación y crisis del coronavirus en España. Primeras lecciones. Profesional de la información 29(3), e290304 10.3145/ epi.2020.may.04

Fernández, F. (2020). COVID-19. Reflexiones sobre el liderazgo y la gestión global de la crisis. Instituto Español de Estudios Estratégicos. http://www.ieee.es/Galerias/fichero/docs analisis/2020/DIEEEA16 2020FEDAZN ReyNaya.pdf

Fuchs, C. (2016). Critical Theory of Communication: New Readings of Lukács, Adorno, Marcuse, Honneth and Habermas in the Age of the Internet. Londres: University of Westminster Press. 10.16997/book1

Ginel, F. (2020). México toma medidas contra el COVID-19. Newtral. https://www.newtral.es/ mexico-medidas-coronavirus/20200328/

Gómez, J. A. (2020). Simón, Apartado por el coronavirus: errores y aciertos del 'supermédico' al frente de la crisis. El Español. https://www.elespanol.com/ ciencia/salud/20200330/simon-apartadocoronavirus-errores-aciertos-supermedicofrente/478703213 0.html

Green, J., Edgerton, J., Naftel, D., Shoub, K. y Cranmer, S.J. (2020). Elusive consensus: Polarization in elite communication on the COVID-19 pandemic. Science Advances, 6(28),. 10.1126/sciadv.abc2717

Habermas, J. (1984). The Theory ofCommunicative Action. Volume 1. Boston: Beacon Press. 
Han, B.C (2014a). En el enjambre. Barcelona: Herder.

Han, B.C. (2014b). Psicopolítica. Barcelona: Herder.

Hegel, G.W.F. (1994). Fenomenología del Espíritu. México: Fondo de Cultura Económica.

Heyman, D. y Shindo, N. (2020). COVID-19: what is next for public health?. The Lancet, 395(10224), 542-545. 10.1016/S01406736(20)30374-3

Infobae (2020). Dos meses con la epidemia: la ruta del COVID-19 en México. https://www. infobae.com/america/mexico/2020/04/28/ dos-meses-con-la-epidemia-la-ruta-delcovid-19-en-mexico/

Kouzy, R., Abi, J., Kraitem, A., El-Alam, M., Karam, B., Adib, E., Zarka, J., Traboulsi, C., Akl, E. y Baddour, K. (2020). Coronavirus Goes Viral: Quantifying theCOVID-19 Misinformation Epidemic on Twitter. Cureus, 12(3), e 7255. 10.7759/cureus.7255

Linde, P. (2020). Los dos casos sospechosos por el virus de Wuhan en España dan negativo. El País, 25 de enero de 2020. https://elpais.com/sociedad/2020/01/24/ actualidad/1579871358 540657.html

Mancilla, S. (2020). Coronavirus en México 6 de diciembre: Resumen de noticias, casos y muertes. AS México, 6 de diciembre de 2020. https://mexico.as.com/mexico/2020/12/06/ actualidad/1607276848 934613.html

Marcuse, H. (1964). One-dimensional man. Studies in the Ideology of Advanced Industrial Society. Boston: Beacon Press.

Marcuse, H. (1968). Negations: Essays in Critical Theory. Londres: Penguin.

Marcuse, H. (1969). Repressive Tolerance. En R. Wolff, B. Moore y H. Marcuse. A Critique of Pure Tolerance. pp. 81 - 123. Boston: Beacon Press

Meng, J. y Berger, B. (2013). An integrated model of excellence leadership in public relations: Dimensions, measurement, and validation.
Journal of Public Relations Research, 25(2), 141-167. 10.1080/1062726X.2013.758583

Meza, L. (2020). El liderazgo resiliente ante el COVID-19. Forbes. https://www.forbes.com. $\underline{\mathrm{mx} / \mathrm{el}-\text { liderazgo-resiliente-ante-el-covid-19/ }}$

Moreno, A., Fuentes, C. y Navarro, C. (2020). Covid-19 communication management in Spain: Exploring the effect of informationseeking behavior and message reception in public's evaluation. Profesional de la información 29(4), e290402. 10.3145/ epi.2020.jul.02

Navarro, B. (2020). Trump admite que siempre quiso 'minimizar' el coronavirus. La Vanguardia, 10 de septiembre de 2020. $\quad$ https://www.lavanguardia.com/ internacional/20200910/483391672845/ trump-woodward-coronavirus-minimizarrage.html

OMS (2020). Risk communication and community engagement readiness and response to coronavirus disease (COVID-19). Interim guidance. https://apps.who.int/iris/bitstream/ handle/10665/331513/WHO-2019-nCoVRCCE-2020.2-eng.pdf

Pérez-Dasilva, J., Meso-Ayerdi, K. y MendigurenGaldospín, T. (2020). Fake news y coronavirus: detección de los principales actores y tendencias a través del análisis de las conversaciones en Twitter. Profesional de la Información, 29(3), e290308. 10.3145/ epi.2020.may.08

Pérez-Díaz, P., Arroyas, E. y Zamora, R. (2020). La construcción de la agenda de los cibermedios. Estudio comparativo con las preferencias temáticas de lectores y usuarios de Twitter. Revista Latina de Comunicación Social, 75, 225-244. 10.4185/RLCS-2020-1424

Robinson, A. (2020). El presidente de México minimiza la gravedad de la pandemia. La Vanguardia, 19 de marzo de 2020. https://www.lavanguardia.com/ internacional/20200319/474261705184/ mexico-amlo-covid-19.html

Salmerón, U. (2020). Coronavirus en México: resumen, muertos y casos de hoy 30 de marzo. 
https://mexico.as.com/mexico/2020/03/30/ tikitakas/1585578603 567991.html

Segado, F., Díaz, J. y Navarro, N. (2020). Emociones y difusión de noticias sobre el cambio climático en redes sociales.
Influencia de hábitos, actitudes previas y usos y gratificaciones en universitarios. Revista Latina de Comunicación Social, 75, 245-269. $\underline{10.4185 / R L C S-2020-1425}$ 